\title{
ESTUDO DA RECICLAGEM DE CÉluLAS NA PRODUÇÃO BIOLÓGICA DE ETANOL ${ }^{1}$
}

\author{
Tadeu Alcides MARQUES ${ }^{2 *}$, Gil Eduardo SERRA ${ }^{3}$
}

\begin{abstract}
RESUMO
Nas destilarias de álcool o conteúdo de etanol, na suspensão de levedura reciclada, gira em torno de $2 \%$ a $3 \%$. A reciclagem de células é realizada tanto em fermentações em batelada, como nas contínuas. A fermentação alcoólica e a recuperação de células de leveduras foram avaliadas em laboratório. A levedura recuperada, por centrifugação, nos experimentos laboratoriais, foi tratada e novamente inoculada em novo meio fermentativo para avaliar o efeito tóxico do etanol e de outros metabólitos nas fermentações subseqüentes. A cepa Saccharomyces cerevisiae IZ-1904 utilizada foi inoculada em meio de melaço diluído contendo $180 \mathrm{~g} \mathrm{~L}^{-1}$ e $310 \mathrm{~g} \mathrm{~L}^{-1}$ de açúcares redutores totais (ART), com três repetições. O tratamento da levedura recuperada constou de dupla centrifugação e ressuspensão em água e vinho. Foram realizadas oito fermentações, a primeira com fermento multiplicado e as demais com a reciclagem de células das fermentações anteriores. O elevado teor de açúcar foi necessário para obtenção da concentração alcoólica desejada no vinho e, assim, conferir inibições e toxicidades detectáveis. Nas fermentações com concentração de etanol menor que $6,4 \%$ (v $\mathrm{v}^{-1}$ ) o efeito tóxico ou inibidor não foi detectado. A inibição pelo etanol e por outros componentes foi detectada sobre as leveduras e os resultados mostraram que a redução dos componentes reciclados com a levedura pode melhorar o processo fermentativo.

Palavras-chave: fermentação alcoólica; reciclagem; inibição; metabólitos.
\end{abstract}

\section{SUMMARY}

THE STUDY OF RECYCLE IN THE BIOLOGICAL PRODUCTION OF ETHANOL. In alcohol distilleries the ethanol content in recycled yeast suspension range from $2 \%$ to $3 \%$. Recycling yeast cells is a useful tool to inoculate another fermentation batch or to continuous fermentation. The ethanolic fermentation and yeast recovering were evaluated in laboratory. The yeast suspension recovered from the wine, by centrifugation, was treated before re-inoculation in new fermentation media, to evaluate the ethanol and other metabolites toxic effect influences in the next fermentations batch. The Saccharomyces cerevisiae IZ-1904 strain was used to inoculate molasses medium with $180 \mathrm{~g} \mathrm{~L}^{-1}$ and $310 \mathrm{~g} \mathrm{~L}^{-1}$ of total reducing sugars (TRS). The yeasts recovering treatment was made with double centrifugation and yeast suspension in water and wine. Eight sequential batch fermentations were done, each with three replications. The first fermentation with fresh yeast, and others with recycled cells. The high sugar content was necessary to generate elevated ethanol concentration in the wine, and to confer hard fermentation conditions so the effects of any toxic compounds were introduced and more easily detected. In fermentations with less than $6.4 \%$ ethanol $\left(\mathrm{v} \mathrm{v}^{-1}\right)$ there was no toxic effect detected. The ethanol and other metabolites inhibition on yeast were detected and the results showed that the reduction of those components from the recycled yeast suspension might optimize the fermentation process. Ethanol production and yeast death rate were affected by the recycling of ethanol. Keywords: alcoholic fermentation; recycle; metabolites; inhibition.

\section{1 - INTRODUÇÃO}

Devido à importância socioeconômica da produção biológica de etanol no Brasil e no mundo, tendo em vista a utilização deste produto em indústrias de alimentos e, como fonte combustivel ecologicamente correta, estudos visando a obtenção de melhores procedimentos tecnológicos no processo fermentativo tornam-se de fundamental importância. Observa-se que durante a fermentação alcoólica, a presença do álcool etílico ocasiona queda na viabilidade celular $[1,4,26] \mathrm{e}$ esta queda ocorre com maior intensidade quando o álcool é gerado endogenamente $[8,9,12,16,18,20]$. Ocorre também, durante a fermentação alcoólica, a produção de n-propanol, isobutanol, isoamílico e amílico $[6,11,13,14,19]$, que são álcoois superiores, componentes do óleo fúsel [27], que podem ser sintetizados

\footnotetext{
Recebido para publicação em 12/08/2002. Aceito para publicação em 12/07/2004 (000954).

2. ${ }^{2}$ Faculdade de Agronomia - UNOESTE - Presidente Prudente - SP. E-mail: tmarques@prudenet.com.br

${ }^{3}$ Departamento de Tecnologia de Alimentos - FEA - UNICAMP - Campinas - SP

* A quem a correspondência deve ser enviada.
}

pelo metabolismo direto das leveduras, em pequenas proporções [7, 23, 27]. O etanol, isopropanol, propanol e butanol afetam a membrana lipoprotéica, podendo assim comprometer a viabilidade celular [15], sendo que o teor de etanol inibitório ao crescimento celular é de $56,6 \mathrm{~g} \mathrm{~L}^{-1}$ [5]. Geralmente, os estudos em fermentação alcoólica são realizados com a finalidade de otimizar a produção de bebidas [2], sendo assim todos os parâmetros utilizados para a condução da fermentação estão bem longe dos parâmetros utilizados nas destilarias brasileiras, como temperatura de fermentação e tempo de fermentação [17, 21]. As destilarias alcoólicas brasileiras operam com o sistema de fermentação denominado "Melle-Boinot" ou com fermentação contínua $[3,10,24]$, nos quais o microrganismo (levedura) é reciclado por fermentações consecutivas, durante toda a safra canavieira. $O$ estudo da reciclagem torna-se de vital importância quando da análise dos teores de compostos tóxicos à fermentação, visto que, se eles são produzidos durante a fermentação, podem acumularse no inóculo promovendo perdas de viabilidade [15, 22], abaixando a eficiência e piorando a produtividade industrial. O presente trabalho estudou a relação entre eficiência fermentativa, rendimento, teor de etanol no vinho, cinética de produção do $\mathrm{CO}_{2}$ e produção de álcoois superiores, com a reciclagem de células. 


\section{2 - MATERIAL E MÉTODOS}

\section{1 - Microrganismo}

A levedura utilizada para a condução da fermentação alcoólica foi a Saccharomyces cerevisiae (IZ 1904), proveniente do Instituto Zimotécnico da ESALQ- USP, Piracicaba-SP.

\subsection{1 - Meio para manutenção}

Foi utilizado o meio YEPD sólido, contendo ( $\left.\mathrm{g} \mathrm{L}^{-1}\right)$ : glicose-20,0; peptona-20,0; extrato de levedura-10,0; ágar-18,0; água destilada para 1000mL.

\subsection{2 - Manutenção da cultura}

A cultura de S. cerevisiae IZ 1904 foi preservada em tubos com meio YEPD sólido, inclinado, sob refrigeração a $5^{\circ} \mathrm{C}$. A renovação das células foi feita antes da ativação da cultura, por repicagem de células no meio, e incubação a $30^{\circ} \mathrm{C}$ durante 48 horas.

\subsection{3 - Delineamento experimental}

Os experimentos de $180 \mathrm{~g}$ e de $310 \mathrm{~g}$ de açúcares redutores totais (ART) por litro no mosto foram conduzidos de maneira análoga, por oito ciclos consecutivos, a partir da reciclagem do fermento do ciclo anterior. $\mathrm{O}$ final da fermentação foi determinado pelo fim da liberação de $\mathrm{CO}_{2}$, medido por pesagens horárias.

O meio de fermentação inoculado com células, na concentração de $10 \%$ em volume, foi adequadamente homogeneizado e distribuído em frascos de "Erlenmeyers" com três repetições para cada tratamento. Os frascos com $200 \mathrm{~g}$ ( $160 \mathrm{~g}$ de mosto e $40 \mathrm{~g}$ de inóculo) permaneceram sob agitação de 80rpm e temperatura de $32^{\circ} \mathrm{C}$ até o final da fermentação, sendo que posteriormente foram retirados $10 \mathrm{~mL}$ para efetuar as análises. $\mathrm{O}$ vinho remanescente foi separado por centrifugação (5600 x g, $\left.10^{\circ} \mathrm{C}, 10 \mathrm{~min}\right)$, e a biomassa oriunda de cada frasco, foi ressuspensa em novo meio de fermentação, em frasco correspondente, iniciando-se o $2^{\circ}$ ciclo fermentativo. Esse inóculo era em seguida completado a $40 \mathrm{~g}$ com vinho e água, para simular a situação industrial (3\% de etanol) e acertado o pH a 2,5 com ácido sulfúrico.

\subsection{4 - Meio para fermentação}

O melaço foi diluído e autoclavado na concentração de $34^{\circ}$ Brix, sendo posteriormente diluído a aproximadamente $180 \mathrm{~g}$ de ART por litro, para o primeiro ensaio com reciclagem de levedura, e diluído a $310 \mathrm{~g}$ de ART por litro para o segundo ensaio com reciclagem de levedura.

\subsection{5 - Métodos analíticos}

- Açúcares redutores

Os açúcares redutores foram determinados pela técnica de Somogyi e Nelson, segundo TRÍBOLI [25].

\section{- Etanol e álcoois superiores}

Foram determinados por cromatografia gasosa, com coluna HP-FFAP capilar, $50 \mathrm{~m}$, temperatura de injeção $120^{\circ} \mathrm{C}$, gradiente de $60^{\circ} \mathrm{C}$ a $200^{\circ} \mathrm{C}$, elevando-se $2^{\circ} \mathrm{C}$ por minuto; detector a $220^{\circ} \mathrm{C}$ e fluxo de $\mathrm{He}$ de $1 \mathrm{~mL} \mathrm{~min}{ }^{-1}$.

\section{3 - RESULTADOS E DISCUSSÃO}

Com 180g ART L-1 obteve-se um teor alcoólico final médio de $5,3 \mathrm{~g}^{100 \mathrm{~g}^{-1}}$ (cerca de $6,8 \% \mathrm{v} \mathrm{v}^{-1}$ ), o que leva a concluir que estes teores de açúcar produzem álcool em quantidade insuficiente para causar inibição significativa da levedura, pois BUENO NETO [5] relatou que somente acima do teor de $7,2 \% \mathrm{v} \mathrm{v}^{-1}$ ocorreu inibição para o crescimento celular. GHOSE \& TYAGI [10], por sua vez, relataram que o teor de etanol de $11,1 \% \mathrm{v} \mathrm{v}^{-1}$ promoveu a redução da velocidade de crescimento celular para zero, ocorrendo apenas a liberação do etanol intracelular, e acima de 14,5\% não ocorreu mais produção nem liberação de etanol.

Por outro lado, esse resultado indica que com mosto de $180 \mathrm{~g}$ ART $\mathrm{L}^{-1}$ a fermentação desenvolveu-se dentro dos parâmetros normais e típicos de fermentação alcoólica.

Nas Figuras 1 e 2 observa-se que o tempo de fermentação foi muito diferente ao comparar os mostos com $180 \mathrm{~g}$ e $310 \mathrm{~g}$ ART L ${ }^{-1}$. Naturalmente, esta diferença de comportamento deve-se ao fato de que teores elevados de ART no início da fermentação podem promover uma inibição e acarretar uma demora para o consumo destes açúcares. Contudo, é interessante salientar que as fermentações alimentadas com mosto de 180 gARTL $^{-1}$ apresentaram curvas semelhantes desde a primeira fermentação até a oitava, demonstrando que nesta concentração não ocorreram alterações que se somassem durante as reciclagens. Nas fermentações com mosto de $310 \mathrm{~g}$ de ART $\mathrm{L}^{-1}$, o comportamento foi bem diferente, sendo que ocorreram grandes alterações na cinética de liberação de $\mathrm{CO}_{2}$, demonstrando que nesta concentração de açúcares no mosto alguns componentes passaram para as fermentações em seqüência.

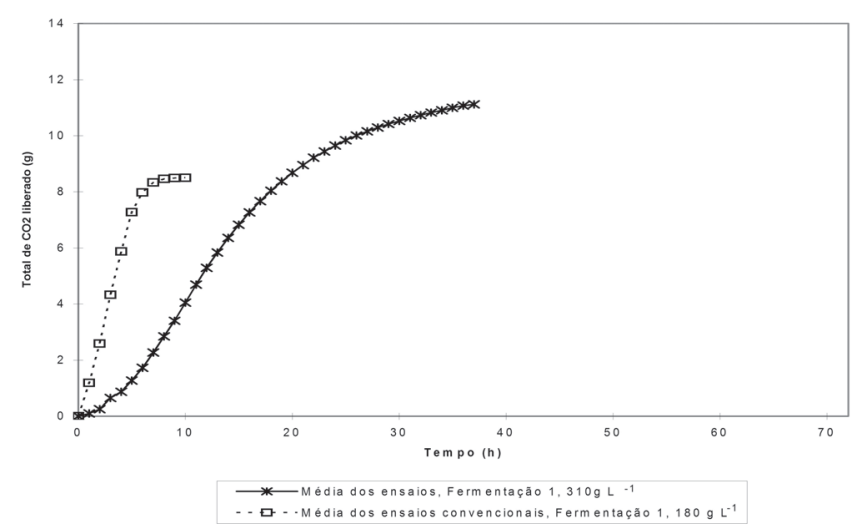

FIGURA 1. Comparação da cinética de liberação de $\mathrm{CO}_{2}$ para ensaios com mosto de $180 \mathrm{~g}_{\text {ART } \mathrm{L}^{-1}}$ e $310 \mathrm{~g}$ ART $\mathrm{L}^{-1}$, na primeira fermentação. 


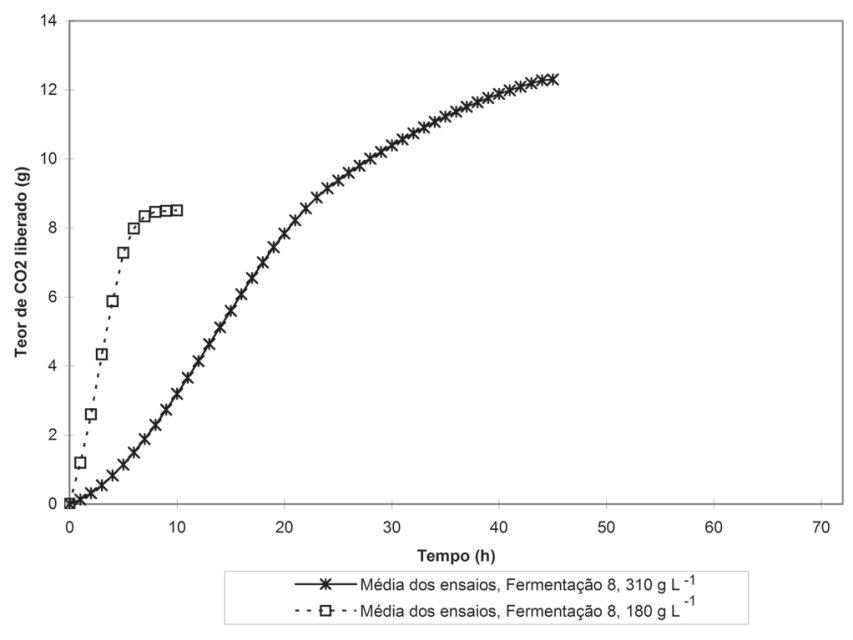

FIGURA 2. Comparação da cinética de liberação de $\mathrm{CO}_{2}$, para ensaios com mosto de $180 \mathrm{~g} \mathrm{ART} \mathrm{L}^{-1}$ e $310 \mathrm{~g} \mathrm{ART} \mathrm{L}^{-1}$, na oitava fermentação.

Na Figura 3 pode ser observado que os valores de concentração de etanol (V\%) para as fermentações com mosto de $310 \mathrm{~g} \mathrm{~L}^{-1}$ sempre estiveram acima das fermentações com mosto de $180 \mathrm{~g} \mathrm{~L}^{-1}$, com exceção da sétima fermentação. A eficiência e o rendimento para as fermentações com mosto de $180 \mathrm{~g} \mathrm{~L}^{-1}$ praticamente permaneceram em um patamar básico. Nas fermentações com mosto de $310 \mathrm{~g} \mathrm{~L}^{-1}$, os rendimentos em etanol foram maiores nas primeiras fermentações se comparados àqueles onde se utilizam mosto de concentração de $180 \mathrm{~g} \mathrm{~L}^{-1}$. No entanto, com o passar das reciclagens, foram caindo e chegaram na oitava reciclagem com valores bem inferiores.

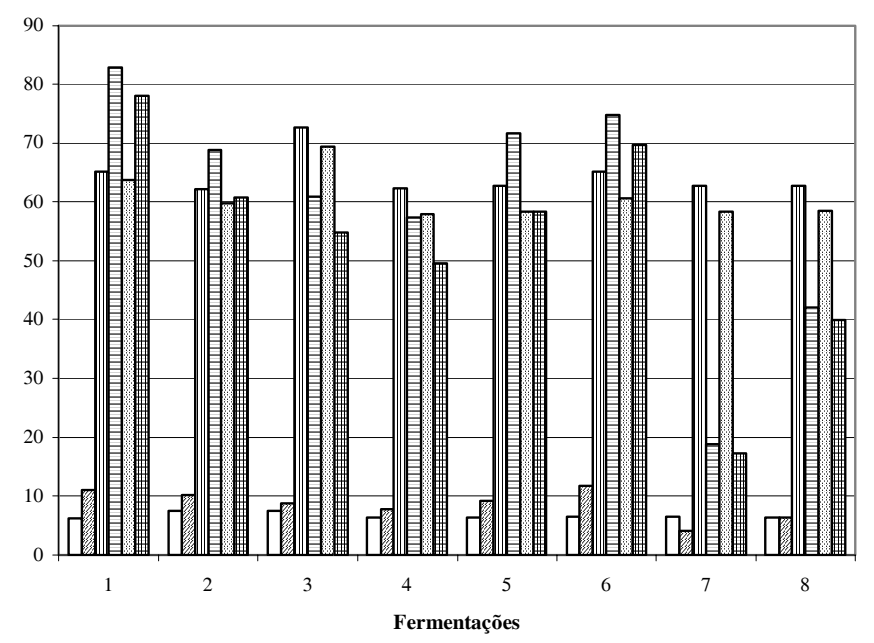

\begin{tabular}{|c|c|}
\hline $\begin{array}{l}\text { 口Etanol V\% - } 180 \mathrm{~g} \mathrm{~L}^{-1} \\
\text { ⿴囗十 Eficiência da levedura - } 180 \mathrm{~g} \mathrm{~L}^{-1} \\
\text { ه Rendimento da fermentação - } 180 \mathrm{~g} \mathrm{~L}^{-1}\end{array}$ & $\begin{array}{l}\text { Etanol V\% - } 310 \mathrm{~g} \mathrm{~L}^{-1} \\
\text { 目Eficiência da levedura - } 310 \mathrm{~g} \mathrm{~L}^{-1} \\
\text { 田Rendimento da fermentação - } 310 \mathrm{~g} \mathrm{~L}^{-1}\end{array}$ \\
\hline
\end{tabular}

FIGURA 3. Dados comparativos entre fermentações com $180 \mathrm{~g}$ ART $L^{-1}$ e 310 gART $L^{-1}$.

Com relação à cinética das fermentações pode-se dizer que as velocidades máximas de produção de $\mathrm{CO}_{2}$ (rp max.) foram iguais para as oito reciclagens, quando o mosto utilizado continha $180 \mathrm{~g} \mathrm{~L}^{-1}$, apresentando o valor médio de $1,70 \mathrm{~g} \mathrm{~h}^{-1}$. Nas fermentações com $310 \mathrm{~g} \mathrm{\textrm {L } ^ { - 1 }}$ obteve-se média de $0,54 \mathrm{~g} \mathrm{~h}^{-1}$, com valores variando de 0,36 a $0,75 \mathrm{~g} \mathrm{~h}^{-1}$. Esta variação demonstra a forte inibição que ocorreu com a reciclagem $[8,9,12,16,18,20]$. Considerando os ensaios com $310 \mathrm{~g} \mathrm{~L}^{-1}$ de ART no mosto, puderam ser detectadas variações do teor de diversos álcoois nos vinhos: O teor de metanol no vinho variou de zero ppm na primeira fermentação ao valor de 107 ppm na quarta fermentação; o teor de n-propanol variou de $42 \mathrm{ppm}$ na terceira fermentação a 154ppm na sexta fermentação; isobutanol variou de 18 ppm na quarta fermentação a $117 \mathrm{ppm}$ na oitava fermentação; o normal butanol variou de zero ppm na primeira fermentação a 218ppm na quinta fermentação; o álcool amílico variou de 53ppm na terceira fermentação a 213ppm na oitava fermentação; os componentes secundários variaram de 140ppm na segunda fermentação a 663ppm na oitava fermentação. Fatos estes que salientam o acúmulo gradual de componentes secundários durante as reciclagens sucessivas, com valores bem inferiores aos citados na literatura [6, 11, 13, 14, 19, 27], promovendo inibições.

\section{4 - CONCLUSÕES}

- A interferência no metabolismo devido à reciclagem de células torna-se mais clara à medida que aumenta-se a concentração de açúcares no mosto e, por conseqüência o teor de etanol no vinho fermentado.

- A interferência do etanol na fermentação alcoólica é mais preocupante em fermentações com altas concentrações de açúcar no mosto.

- Em ensaios que visem o estudo da produção e teores inibitórios de subprodutos da fermentação alcoólica, é necessária uma atenta observação na concentração de açúcares no meio fermentativo.

- Uma centrifugação adicional visando a diminuição dos componentes que acompanham as células de levedura na reciclagem é uma operação que reduzirá efeitos inibidores de fermentações.

\section{5 - REFERÊNCIAS BIBLIOGRÁFICAS}

[1] AIBA, S.; SHODA, M.; NAGATANI, M. Kinetics of product inhibition in alcohol fermentation. Biotechnology and Bioengineering, New York, v. 10, n. 4, p. 845-864, 1968.

[2] AMERINE, M.A.; CRUESS, W.V. The technology of wine making. 1ed. New York: AVI Publ, 1960. 709p.

[3] AMORIM, H.V.; OLIVEIRA, A.J.; ZAGO, E.A. Fermentação descontínua: otimização do processo Melle-Boinot. In: SEMANA DE FERMENTAÇÃO ALCOÓLICA “JAIME ROCHA DE ALMEIDA", 4. 1985, Piracicaba. Anais. Piracicaba: ESALQ/STAB, 1985. p. 114-121.

[4] BROWN, S.W.; OLIVER, S.G.; HARRISON, D.E.F.; RIGHELATO, R.C. Ethanol inhibition of yeast growth and fermentation: differences in the magnitude and complexity of the effect. European Journal of Applied Microbiology and Biotechnology, Berlin, v. 11, p. 151-155, 1981. 
[5] BUENO NETO, C.L. Influência da concentracão inicial de células e do tempo de enchimento da dorna no processo descontínuo alimentado de fermentação alcoólica de mosto de melaço de cana-de-açúcar. São Paulo, 1982. 147p. Dissertação (Mestrado em Química) - Escola Politécnica, USP.

[6] CACHOT, T.; MÜLLER, M.; PONS, M. Kinetics of volatile metabolites during alcoholic fermentation of cane molasses by Sacch. cerevisiae. Applied Microbiology and Biotechnology, New York, v. 35, n. 4, p. 450-454, 1991.

[7] CASEY, G.P.; MAGNUS, C.A.; INGEDEW, W.M. Highgrowth brewing: effect of nutrition on yeast composition, fermentation ability, and alcohol production. Applied Environmental Microbiology, Baltimore, v. 48, n. 3, p. 638-646, 1984.

[8] D'AMORE, T.; PANCHAL, C.J.; STEWART, G.G. The effect of osmotic pressure on the intracellular accumulation of ethanol in Sacch. cerevisiae during fermentation in wort. Journal of the Institute of Brewing, London, v. 93, p. 472-476, 1987.

[9] D'AMORE, T.; PANCHAL, C.J.; STEWART, G.G. Intracellular ethanol accumulation in Sacch. cerevisiae during fermentation. Applied and Environmental Microbiology, Washington, v.54, n.1, p.110-114, 1988.

[10] GHOSE, T.K.; TYAGI, R.D. Rapid ethanol fermentation of cellulose hydrolysate: batch versus continuous systems. Biotechnology and Bioengineering, New York, v. 21, p. 1387-1400, 1979.

[11] GUYMON, J.F.; INGRAHAM, J.L.; CROWELL, E.A. The formation of n-propyl alcohol by Sacch. cerevisiae. Archives of Biochemistry and Biophysics, Duluth, v. 95, p. 163-168, 1961.

[12] HOPPE, G.K.; HANSFORD, C.S. Ethanol inhibition of continuous anaerobic yeast growths. Biotechnology Letters, Kew, v. 4, n. 1, p. 39-44, 1982.

[13] KUNKEE, R.E.; AMERINE, M.A. Yeast in wine-making. In: ROSE, A.H. \& HARRISON, J.S. The yeast. 1 ed. New York: Academic Press, 1970. p. 5-71.

[14] LEÃO, C.; VAN UDEN, N. Effects of ethanol and other alkanols on the kinetics and activation parameters of thermal death in Sacch. cerevisiae. Biotechnology and Bioengineering, New York, v. 24, p. 1581-1590, 1982.

[15] LEÃO, C.; VAN UDEN, N. Effects of ethanol and other alkanols on passive proton influx in the yeast Sacch. cerevisiae. Biochimica et Biophysica Acta, Amsterdam, v. 774, p. $43-48,1984$.

[16] LEITE, S.G.F.; FRANÇA, F.P. Intracellular ethanol and cellular viability of Sacch. cerevisiae. Revista de Microbiologia, São Paulo, v. 21, n. 2, p. 163-165, 1990.

[17] LEME, J.R.A.; LIMA, L.S.; LOPES, C.H.; FERRARI, S.E.; LOPES, J.J.C.; GERMEK, H.A.; OLIVEIRA, E.R. Fermento selecionado IZ-1904. Piracicaba: PLANALSUCAR, 1984. $15 \mathrm{p}$.

[18] LOUREIRO, V.; FERREIRA, H.G. On the intracellular accumulation of ethanol in yeast. Biotechnology and Bioengineering, New York, v. 25, p. 2263-2269, 1983.

[19] MAIORELLA, B.; BLANCH, H.W.; WILKE, C.R. By-product inhibition effects on ethanolic fermentation by Sacch. cerevisiae. Biotechnology and Bioengineering, New York, v. 25, p. 103-121, 1983.

[20] NAGODAWITHANA, T.W.; STEINKRAUS, K.H. Influence of the rate of ethanol production and accumulation on the viability of Sacch. cerevisiae in the presence of acetic acid. Applied Microbiology and Biotechnology, Berlin, v. 34, p. 375-380, 1990.

[21] NAVARRO, J.M. Fermentation alcoolique: influence des conditions de culture sur l'inhibition par l'ethanol. Cellular \& Molecular Biology, Elmsford, v. 26, p. 241246, 1980.

[22] OKOLO, B.; JOHNSTON, J.R.; BERRY, D.R. Toxicity of ethanol, n-butanol and iso-amyl alcohol in Sacch. cerevisiae when supplied separately and in mixtures. Biotechnology Letters, Kew, v. 9, n. 6, p. 431-434, 1987.

[23] OURA, E. Reaction products of yeast fermentations. Process Biochemistry, v. 4, p. 19-35, 1977.

[24] RHEINBOLDT, P.H.H.; LEIMER, K.H.; ROSSELL, C.E.V. Sangria e secagem de levedura-processo CTC. Boletim Técnico Copersucar. Piracicaba, v. 39, p. 8-12, 1987.

[25] TRÍBOLI, E.P.R. Métodos analíticos para o acompanhamento da fermentação alcoólica. São Caetano do Sul: Instituto Mauá de Tecnologia, 1987. 40p.

[26] VAN UDEN, N. Ethanol toxicity and ethanol tolerance in yeast. In: TSAO, G. T. Annual reports on fermentation process. 1ed. New York: Academic Press, 1985. v. 8, p. 11-58.

[27] Weeb, A.D.; Ingraham, J.L. Fusel Oil. Adv. Appl. Microbiol, v. 5, p. 317-353, 1963. 